INTERNATIONAL JOURNAL OF ENGINEERING, SCIENCE AND TECHNOLOGY

www.ijest1-ng.com www.ajol.info/index.php/ijest

C)2021 MultiCraft Limited. All rights reserved

\title{
Assessment of noise pollution at various locations of Gorakhpur
}

\author{
Maharshi Yadav ${ }^{1}$, Ratnesh Kumar Patel ${ }^{1}$, Abhishek Yadav $^{2}$, Gaurav Sharma ${ }^{3}$, Govind Pandey ${ }^{3}$ \\ 1*Department of Chemical Engineering, Madan Mohan Malaviya University of Technology, Gorakhpur, INDIA \\ ${ }^{2}$ Department of Civil Engineering, SRM Group of professional colleges, Lucknow, INDIA \\ *Corresponding Author: e-mail: maharshiyadav@outlook.com Tel +91-8375858788,
}

\begin{abstract}
Noise pollution is one of the major concerns in big cities as well as in the crowded area of small cites, Gorakhpur is fastgrowing city and has many locations with high noise levels. Various crossroads and intersections have traffic issues this causes high noise level. In this study, three locations were selected for noise level assessment, nearby areas of Gorakhnath Temple, BRD medical college and MMMUT. These locations are educational (silent) and low noise level zone but because they situated near traffic roads, which cause high noise levels around them. In this study outside periphery of educational institutions noise level increases due to traffic. Noise level is found to be high due to large number of human activities.
\end{abstract}

Keywords: Noise pollution, Gorakhpur, traffic, silent zone.

DOI: http://dx.doi.org/10.4314/ijest.v13i1.20S

Cite this article as:

Yadav M., Patel R.K., Yadav A., Sharma G., Pandey G. 2021. Assessment of noise pollution at various locations of Gorakhpur. International Journal of Engineering, Science and Technology, Vol. 13, No. 1, pp. 131-137. doi: 10.4314/ijest.v13i1.20S

Received: December 1, 2019; Accepted: February 5, 2021; Final acceptance in revised form: March 31, 2021

This paper was earlier presented at the International Conference on Energy, Environment \& Material Sciences (ICE2M), 1-3 December 2019 and substantially improved for this Special Issue. Guest Editor: Dr. Sri Niwas Singh, Professor (HAG), Department of Electrical Engineering, Indian Institute of Technology Kanpur, 208016 (U.P.) India, former Vice-Chancellor, Madan Mohan Malviya University of Technology Gorakhpur (April 2017 to July 2020).

\section{Introduction}

Noise pollution is a major concern in cities, and it is not causing only irritation, stress and deafness but also causing coronary heart diseases (Datta et al. 2006; Babisch 2014; Peña, Montero, and Rodríguez 2019; European Agency for Safety and Health at Work 2005; Tobías et al. 2015; Münzel et al. 2014), cardiovascular diseases(Ndrepepa and Twardella 2011; Babisch 2008) and cerebrovascular diseases (Fujino, Iso, and Tamakoshi 2007). Daily exposure of noise responsible for mental health and sleeping disorder (Sygna et al. 2014). Noise pollution is increasing problem in India due to high rate of urbanization, road traffic, building and factory's noise. Due to increased risk associated with noise pollution it cannot be ignored compared to the other major pollution, noise pollution is major problem it should be consider and major pollution in India and needs to come up with proper solutions.

\subsection{Noise Pollution In Some Cities of India:}

Noise pollution levels in Visakhapatnam city (India):Sagar and Rao (2006), studied noise level in Visakhapatnam city at RCD hospital, Lawson's Bay Colony, Jagadamba junction, APSRTC Complex junction and Seethammadhara junction and Seaport. All the above zones locations classified as silent, residential, traffic and industrial zones. The researcher finds 44 to $53 \mathrm{dBA}$ noise level in day time near RCD hospital, noise level finds 5 to $10 \mathrm{dBA}$ more than prescribed by the CPCB limit. In residential area noise 
level sometimes cross to 77dBA, otherwise normally it founds in between 45 to 50 dBA(Vidya Sagar and Nageswara Rao 2006). At traffic locations it crosses the $90 \mathrm{dBA}$ and ranges between 70 to $90 \mathrm{dBA}$.

Noise pollution in the city of Kolhapur; Rajeev and Yogesh 2012, conducted noise level assessments in city of Kolhapur Maharastra. The researcher included various zones, Ambai square, University Road area as educational zone, Rajarampuri area as industrial cum residential zone, Rankala lake and New palace area as silent zone. Maximum Leq recorded was $63.71 \mathrm{dBA}$ between 2.00-3.00 pm, while it was minimum (42.51 dBA) during night from 10.00- $11.00 \mathrm{pm}$. The daytimeLeq observed in educational zone was greater than the prescribed CPCB limits during day time, which is $50 \mathrm{dBA}$. Industrial-cum residential zone (Mixed zone) has $72.25 \mathrm{dBA}$ which is below industrial limit but above the residential limit (Hunashal and Patil 2012).

Noise Pollution of Surat city, India; Tandel and Macwan (2011) assess the noise pollution conditions in Surat city (Tandel, Macwan, and Ruparel 2011), researchers find that in educational areas noise limits were varying from 112 to $118 \mathrm{dBA}$, which is much higher from the prescribed limit of pollution norms.

Noise Pollution in Guwahati City; Alam, 2011 done GIS-based assessment of Noise pollution of Guwahati city (Alam 2011), Some commercial locations like Paltan Bazar, Guwahati Club, Ganeshguri, Khanapara, MaligaonCharilali showed higher noise levels (more than $80 \mathrm{~dB}(\mathrm{~A})$ ) than other commercial places as these places are always crowded with all type of vehicles, narrow roads and poor traffic management system. Residential areas were also exceeding the limits and roadside residential areas were crossing the level of 75dBA. Alam finds serious concern in silence zones, 50dBA is limit for the educational zones but in the city it crosses limit due to heavy traffic. Noise Pollution in Meerut, Moradabad, heavy traffic nearby silence zones in various cities of India is one of the major reasons for the high noise level. Singh and Joshi 2010 monitor the noise level in Meerut city(D. Singh and Joshi 2012) during Deepawali festival, surprisingly during deepawali festival residential area shastri nagar find upto 85dBA which is higher than the commercial zone of Meerut (83dBA). In silence zones of city noise level is around 70dBA. Chauhan, Pawar et. al, assess the noise level in Moradabad city (Chauhan et al. 2010), residential zones of the city have noise level variations from $76 \mathrm{dBA}$ to $102 \mathrm{dBA}$ in day time, in night time it varies from 55 to $80 \mathrm{dBA}$. Commercial zones have much higher noise up to 105 $\mathrm{dBA}$ during daytime. Industrial zones have highest noise level of $118 \mathrm{dBA}$, Silence zones of city also cross the limit given in norms.

Almost all cities suffering from noise pollution, big and unplanned cities have major problems of noise pollution.(Khaiwal et al. 2016; Marathe 2012; Goswami and Swain 2017; Garg and Maji 2016; Subramani and Sivaraj 2012; Zannin and Sant'Ana 2011; Pucher et al. 2005) In unplanned cities various small-scale industries, educational institutes, hospitals and heavy load of traffic are getting combined and increasing noise. In planned city noise pollution problems reduces due different area allowed for different zones. In this study noise pollution level at different locations was assessed with guidelines of CPCB

\section{Study Area}

Gorakhpur is a big and fast-growing city of the Uttar Pradesh, India. Gorakhpur district has a population of 44.41 lakhs (4.44 million) and city area population is about 7 lakhs. All major institutions and universities are established in city areas. In this study three locations are selected which are very important places in Gorakhpur. MMM University of Technologyand BRD Medical College is educational institutions, and third one is Gorakhnath Temple. These locations are important because they are situated near to heavy traffic road specially Gorakhnath Temple and BRD Medical College.

In this study, the following three locations of Gorakhpur city is chosen-

\begin{tabular}{|l|l|l|}
\hline \multicolumn{1}{|c|}{ [1] MMM University of Technology } & \multicolumn{1}{|c|}{ [2] BRD Medical College } & \multicolumn{1}{|c|}{ [3] Gorakhnath Temple } \\
\hline \multicolumn{1}{|c|}{$\left[\begin{array}{l}\text { [Z } \\
\hline \text { Ambedkar Hostel }\end{array}\right.$} & Near Pharmacy & Main temple \\
\hline Raman Hostel & Outside OPD & Pond area \\
\hline WorkShop & Outside X-ray room & Outside main temple \\
\hline Faculty Colony & Near orthopedic & Digvijaynath Temple \\
\hline University Gate & Hospital Main Gate & Temple Main gate \\
\hline Academic Block & & \\
\hline
\end{tabular}

Colleges, Hospitals and Universities is consider as Silent Zone according to CPCB guidelines, locations of study come under silent zone (Pathak, Tripathi, and Mishra 2008).

\section{Instrument and Method}

Bruel and Kjaer, Denmark 2232 (B\&K 2232) sound level meter is used for the measurement of noise level, it is a digital electronic device and suitable for the Community and industrial noise measurements, Checking compliance with noise rating, recommendations, Traffic noise measurements and Front-end for other equipment. B\&K 2232 has a digital liquid crystal display with $0.1 \mathrm{dBA}$ display resolution. Overload, under range and low battery warning. B\&K 2232 is lightweight (460 gram) and easy 
handling operating device with high precision. B\&K 2232 has range of measurement in between $34 \mathrm{~dB}$ to $130 \mathrm{dBA}$, this range is divided in two sub ranges 34 to $94 \mathrm{~dB}$ and 70 to $130 \mathrm{dBA}$.

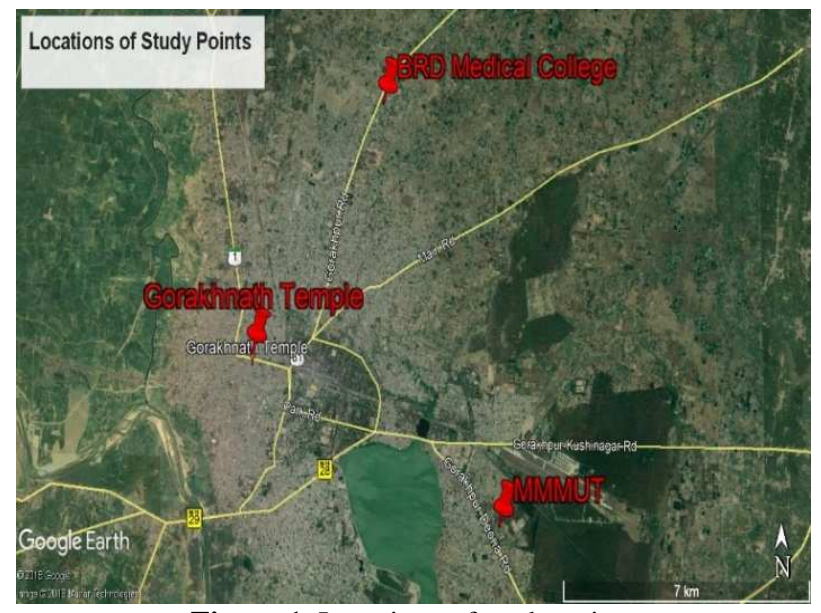

Figure 1. Locations of study points

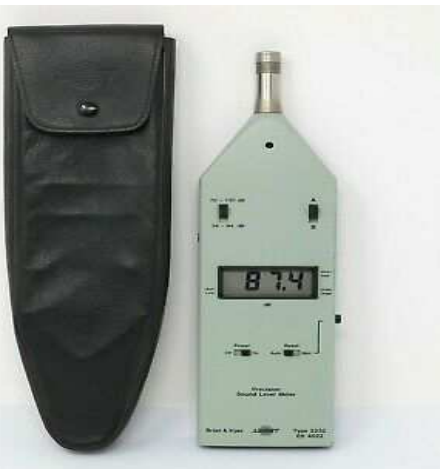

Figure 2. Noise Level meter Make Bruel and Kjaer, Denmark 2232

While the measurement of noise level using B\&K 2232 it is important to keep instrument 1.2 to 1.5 meters above to the ground as well as instrument should be 1 meter away from the chest to avoid error in measurement(Bruel\& Kjaer 1964; Kumar, Pandey, and Mishra 2014; Krueger et al. 2003; P. K. Singh et al. 2016; Moussa et al. 2013).

The time duration has been selected to cover the most active part of the day, from 9:00 am morning to follow by noisy day. For measurement of sound level in particular hour we evaluated continuously for 5 minutes and taken reading after every 15 seconds so in 5 minutes total 20 reading is taken and then later calculations is done by following formula

$$
L_{e q}=10 \log _{10} \sum_{i=1}^{n} L_{i} / 10 \times T_{i}
$$

where,

$\mathrm{n} \quad=$ total no of sound samples

$\mathrm{L}_{\mathrm{i}}=$ noise level of any $\mathrm{i}^{\text {th }}$ sample

$\mathrm{T}_{\mathrm{i}}=$ time duration of $\mathrm{i}^{\text {th }}$ sample expressed as a fraction of total time sample

\section{Results and Discussion}

Graphs are plotted between sound/noise level and time duration of daytime for all locations. According to the Central pollution control board (CPCB) (Garg et al. 2016) 50dBA is limit for the silent zones. In BRD medical college noise level at various locations fluctuates with daytime, maximum noise activity occurs in orthopedic areas and main gate of medical college. Noise level high nearby orthopedic is due to large human activities. Almost all places in medical college is crossing CPCB limit mostly because of large number of human activities as well as because of traffic noise, noise level find high at those places where less human activities because of locations were not far away from road and road noise can be heard very clearly. 


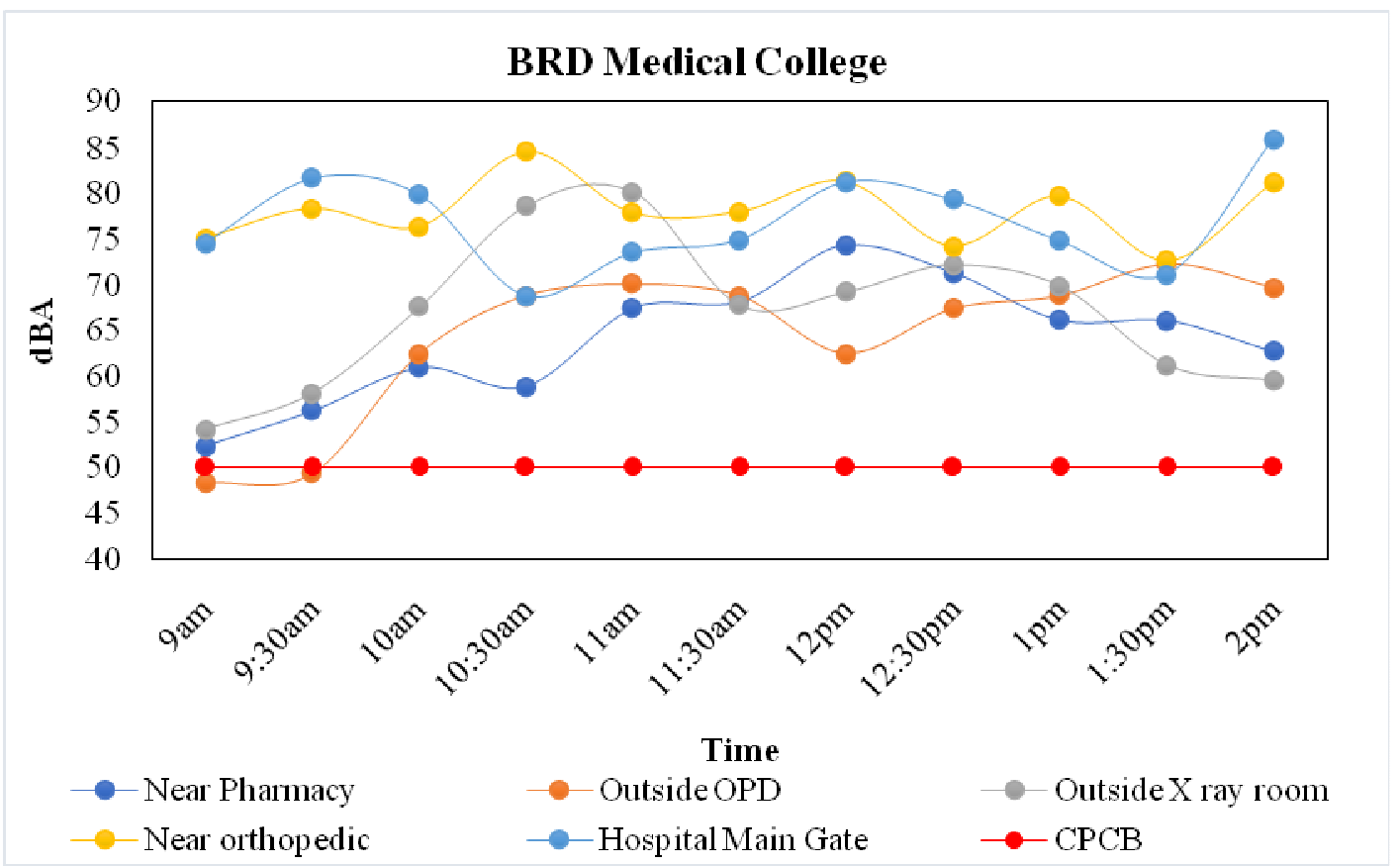

Figure 3.Noise level variation at BRD medical college

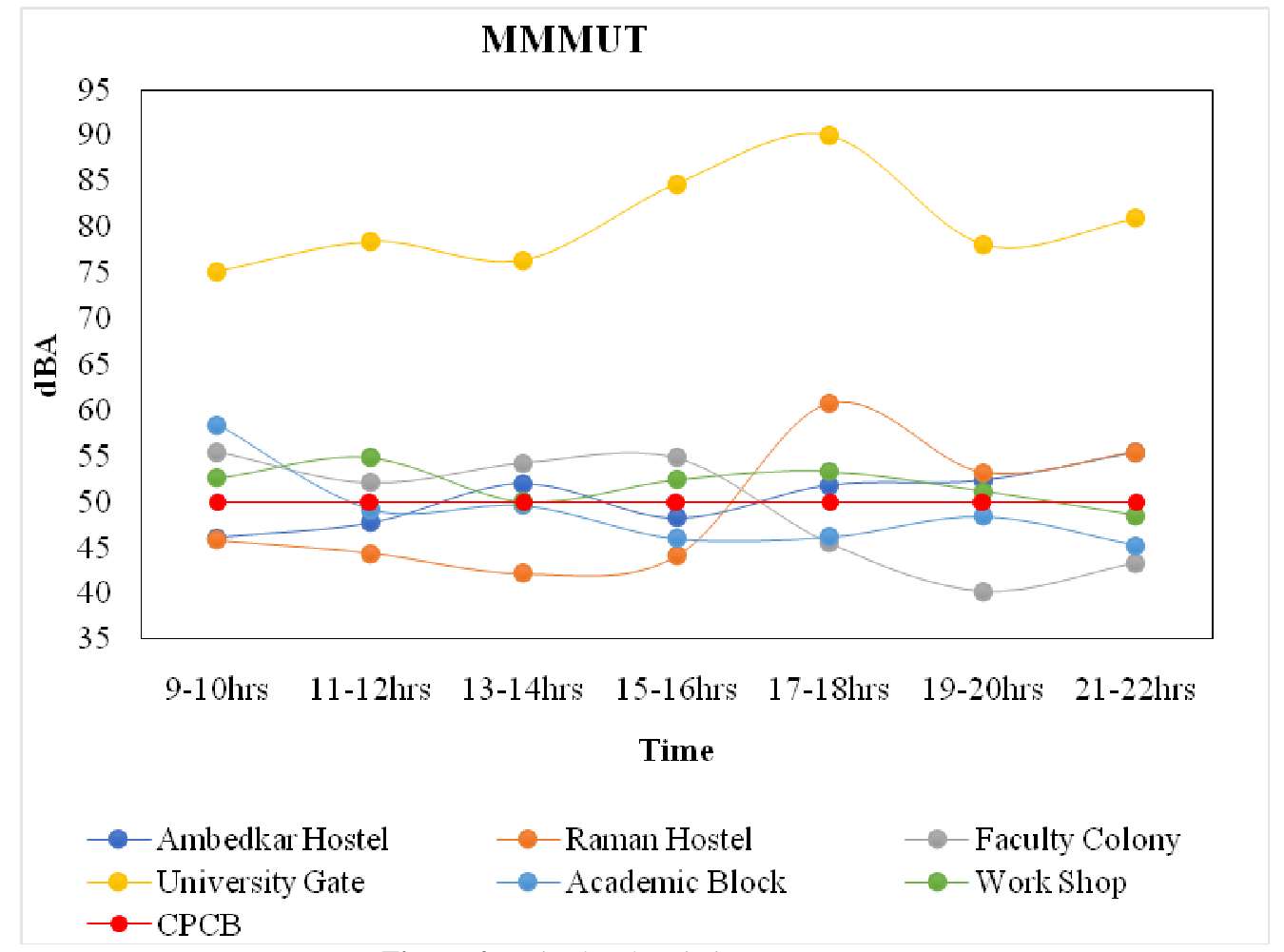

Figure 4. Noise level variation at MMMUT 


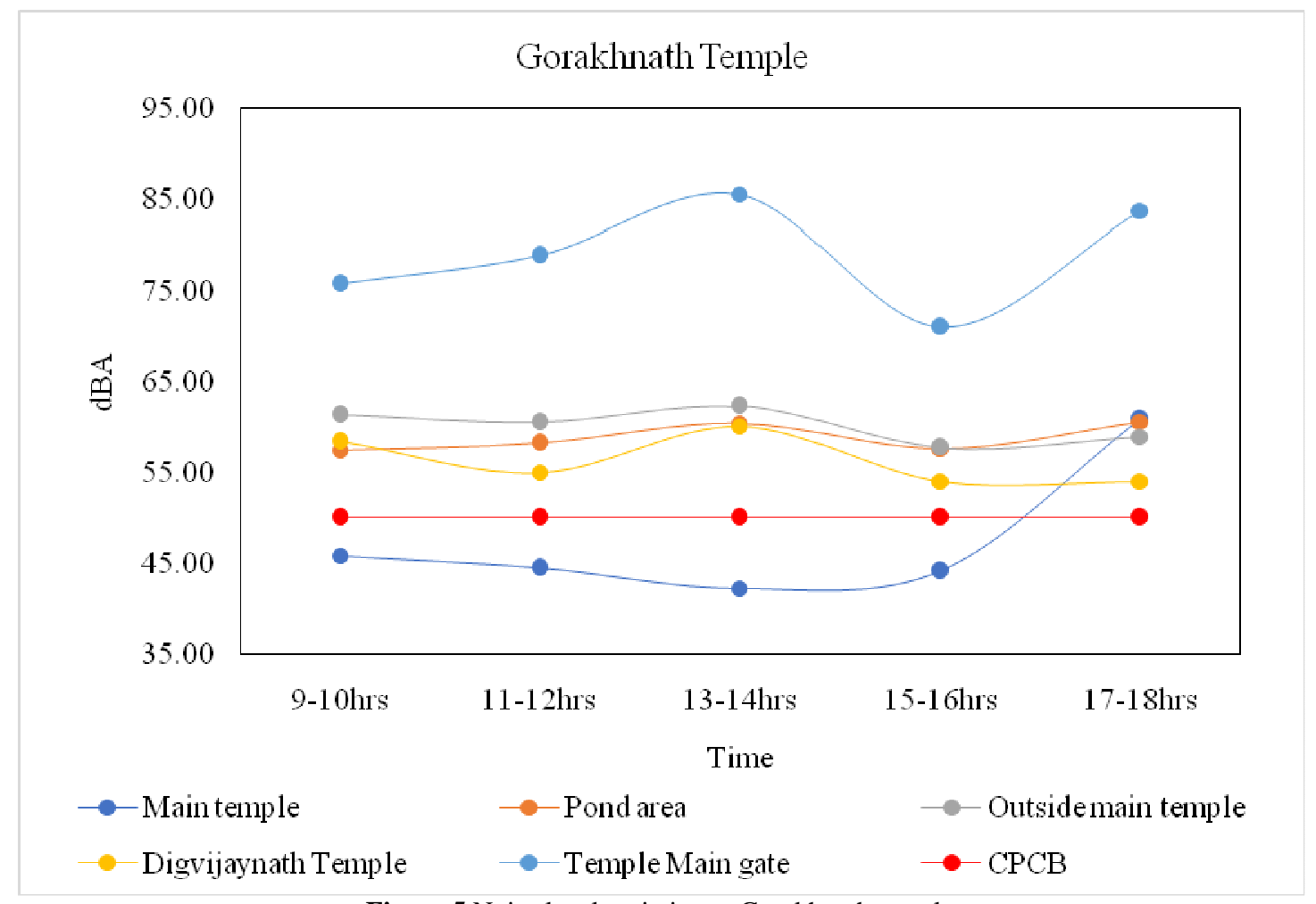

Figure 5.Noise level variation at Gorakhnath temple

In MMMUT noise level varies from $40 \mathrm{dBA}$ to $90 \mathrm{dBA}$, minimum noise finds in faculty colony and maximum noise occurs at main gate of university. Noise level in university varies around 50dBA, here also maximum noise observed at main gate due to traffic noise. In Gorakhnath temple were high human activities occurs but due proper sequencing of people noise level doesn't go much higher, comparing to the medical college and temple, temple have much higher human activities but noise level is low. Outside traffic at all places were high but temple and faculty colony were much away from the road, maybe one of the possible reason for low noise.

\section{Conclusions}

Noise level finds to be high at locations nearby to the road. Main gate, which is near to road, finds maximum noise all three locations. locations away from the roadside finds to be less noise, universities and colleges are in silent zone but during studies it is realises that roadside traffic have potential impact on these areas. This study shows that need of proper noise level assessment with respect to distance from roadside for silent zone area. Locations which comes under the silent zones and near to the heavy traffic roadside they need to assess and need to find actually how much noise impact of traffic on silent for keeping safeguard towards noise pollution.

\section{References}

Alam, Wazir. 2011. "GIS Based Assessment of Noise Pollution in Guwahati City of Assam, India." International Journal of Environmental Sciences. https://doi.org/10.6088/ijes.00202020034.

Babisch, Wolfgang. 2008. "Road Traffic Noise and Cardiovascular Risk.” Noise and Health. https://doi.org/10.4103/14631741.39005 . . 2014. "Updated Exposure-Response Relationship between Road Traffic Noise and Coronary Heart Diseases: A MetaAnalysis." Noise and Health. https://doi.org/10.4103/1463-1741.127847.

Bruel \& Kjaer. 1964. "Technical Review to Advanced Techniques in Acoustical, Electrical and Mechanical Measurements: Noise Test Chamber." Larsen \& Son, Denmark 2014.

Chauhan, Avnish, Mayank Pawar, Dharmendra Kumar, Navneet Kumar, and Rajeev Kumar. 2010. "Assessment of Noise Level Status in Different Areas of Moradabad City.” Researcher.

Datta, J. K., S. Sadhu, S. Gupta, R. Saha, N. K. Mondal, and B. Mukhopadhyay. 2006. "Assessment of Noise Level in Burdwan Town, West Bengal." Journal of Environmental Biology. 
European Agency for Safety and Health at Work. 2005. "The Impact of Noise at Work." Facts.

Fujino, Yoshihisa, Hiroyasu Iso, and Akiko Tamakoshi. 2007. "A Prospective Cohort Study of Perceived Noise Exposure at Work and Cerebrovascular Diseases among Male Workers in Japan.” Journal of Occupational Health. https://doi.org/10.1539/joh.49.382.

Garg, N., and S. Maji. 2016. "A Retrospective View of Noise Pollution Control Policy in India: Status, Proposed Revisions and Control Measures.” Current Science. https://doi.org/10.18520/cs/v111/i1/29-38.

Garg, N., A. K. Sinha, V. Gandhi, R. M. Bhardwaj, and A. B. Akolkar. 2016. "A Pilot Study on the Establishment of National Ambient Noise Monitoring Network across the Major Cities of India." Applied Acoustics. https://doi.org/10.1016/j.apacoust.2015.09.010.

Goswami, Shreerup, and Bijay K. Swain. 2017. "Environmental Noise in India: A Review." Current Pollution Reports. https://doi.org/10.1007/s40726-017-0062-8.

Hunashal, Rajiv B., and Yogesh B. Patil. 2012. "Assessment of Noise Pollution Indices in the City of Kolhapur, India." Procedia Social and Behavioral Sciences. https://doi.org/10.1016/j.sbspro.2012.03.310.

Khaiwal, Ravindra, Tanbir Singh, Jaya Prasad Tripathy, Suman Mor, Sanjay Munjal, Binod Patro, and Naresh Panda. 2016. "Assessment of Noise Pollution in and around a Sensitive Zone in North India and Its Non-Auditory Impacts." Science of the Total Environment. https://doi.org/10.1016/j.scitotenv.2016.05.070.

Krueger, W. A., M. Trick, T. H. Schroeder, and K. E. Unertl. 2003. "Calibration of a Room Air Gas Monitor with Certified Reference Gases.” ANAESTHESIST. https://doi.org/10.1007/s00101-003-0598-4.

Kumar, Praveen, Govind Pandey, and Arun Kumar Mishra. 2014. "A Study of Noise Pollution in Some Highway Corridor Near Gorakhpur City." International Journal of Engineering Research \& Technology (IJERT).

Marathe, P D. 2012. "Traffic Noise Pollution." Ijed.

Moussa, Ayman S., Ahmed El-Shafei, Ed Diaz, Tianming Gao, Osama M. Zaytoun, Khaled Fareed, James C. Ulchaker, and J. Stephen Jones. 2013. "Identification of the Variables Associated with Pain during Transrectal Ultrasonography-Guided Prostate Biopsy in the Era of Periprostatic Nerve Block: The Role of Transrectal Probe Configuration." BJU International. https://doi.org/10.1111/j.1464-410X.2012.11689.x.

Münzel, Thomas, Tommaso Gori, Wolfgang Babisch, and Mathias Basner. 2014. "Cardiovascular Effects of Environmental Noise Exposure." European Heart Journal. https://doi.org/10.1093/eurheartj/ehu030.

Ndrepepa, Ana, and Dorothee Twardella. 2011. "Relationship between Noise Annoyance from Road Traffic Noise and Cardiovascular Diseases: A Meta-Analysis." Noise \& Health. https://doi.org/10.4103/1463-1741.80163.

Pathak, Vinita, B. D. Tripathi, and Virendra kumar Mishra. 2008. "Evaluation of Traffic Noise Pollution and Attitudes of Exposed Individuals in Working Place." Atmospheric Environment. https://doi.org/10.1016/j.atmosenv.2007.12.070.

Peña, Odalys Hernández, Gisel Hernández Montero, and Ernesto López Rodríguez. 2019. "Noise and Health." Revista Cubana de Medicina Militar. https://doi.org/10.1016/b978-0-08-102295-5.10411-1.

Pucher, John, Nisha Korattyswaropam, Neha Mittal, and Neenu Ittyerah. 2005. "Urban Transport Crisis in India.” Transport Policy. https://doi.org/10.1016/j.tranpol.2005.02.008.

Singh, Digvijay, and B. D. Joshi. 2012. "Study of Noise Pollution for Three Consecutive Years during Deepawali Festival in Meerut City, Uttar Pradesh (India)." Journal of Environmental Science \& Engineering.

Singh, Pawan Kumar, Rohit Kumar Gupta, Vijay Kumar Mishra, and Dr A K Mishra. 2016. "A comparative study of ambient noise levels at commercial, residential and silent zone in Gorakhpur." International Research Journal of Engineering and Technology.

Subramani, T, and M Kavitha K P Sivaraj. 2012. "Modelling of Traffic Noise Pollution.” International Journal of Engineering Research and Application.

Sygna, Karin, Gunn Marit Aasvang, Geir Aamodt, Bente Oftedal, and Norun Hjertager Krog. 2014. "Road Traffic Noise, Sleep and Mental Health.” Environmental Research. https://doi.org/10.1016/j.envres.2014.02.010.

Tandel, Bhaven, Joel Macwan, and Pratik N Ruparel. 2011. "Urban Corridor Noise Pollution: A Case Study of Surat City, India." Ipcbee .

Tobías, Aurelio, Alberto Recio, Julio Díaz, and Cristina Linares. 2015. "Health Impact Assessment of Traffic Noise in Madrid (Spain)." Environmental Research. https://doi.org/10.1016/j.envres.2014.12.011.

Vidya Sagar, T., and G. Nageswara Rao. 2006. "Noise Pollution Levels in Visakhapatnam City (India).” Journal of Environmental Science and Engineering.

Zannin, Paulo Henrique Trombetta, and David Queiroz De Sant'Ana. 2011. "Noise Mapping at Different Stages of a Freeway Redevelopment Project - A Case Study in Brazil.” Applied Acoustics. https://doi.org/10.1016/j.apacoust.2010.09.014.

\section{Biographical notes}

Maharshi Yadav received M. Tech. in Environmental Engineering from MMMUT, Gorakhpur India in 2018 and Pursuing PhD in Chemical Engineering from MMMUT respectively. His main area of research is Environmental flow assessment, Noise pollution, Environmental monitoring and assessment, Water disinfection and treatment. 
Ratnesh Kumar Patel received M. Tech. in Chemical Engineering from HBTI, Kanpur, India in 2016and Pursuing PhD in Chemical Engineering from MMMUT respectively. His main area of research is Adsorption of pollutant, pollution, Environmental monitoring and assessment, Water and wastewater and treatment. Electrochemical Methods of treatment.

Abhishek Yadav received M. Tech. in Environmental Engineering from MMMUT, Gorakhpur India in 2018, currently assistant professor in SRM group of professional colleges. His field of research pollution monitoring and Encephalitis assessment and control.

Gaurav Sharma received M. Tech. in Environmental Engineering from MMMUT, Gorakhpur India in 2018, his area of research is Water pollution and Encephalitis.

Govind Pandey received PhD degree from IIT Roorkee, have vast experience in pollution research, his main area of research is water and wastewater treatment and health hazards. 